\title{
Partially protective effect of telmisartan on slow healing wounds in diabetic rats: possible role of AGEs-RAGE axis \\ Rasha H. Abdel-Ghany ${ }^{1}$, Nadia Hassan ${ }^{1^{*}}$, Waleed M. Barakat ${ }^{1,2}$ \\ ${ }^{1}$ Department of Pharmacology and Toxicology, Faculty of Pharmacy, Zagazig University, 44519 Zagazig, Egypt \\ ${ }^{2}$ Department of Pharmacology, Faculty of Pharmacy, Tabuk University, Kingdom of Saudi Arabia.
}

*Corresponding author e-mail: nadia_nnr@yahoo.com

\begin{abstract}
Accumulation of advanced glycation endproducts (AGEs) has been found in healthy aging persons and during elevated glucose concentrations. It has been implicated in microvascular and macrovascular damage and delayed wound healing associated with diabetes, presumably through vascular, neurological, or intermediary metabolic modifications. The aim of the present work is to examine the potentially protective effect of telmisartan against diabetes-induced peripheral neuropathy in rats. Diabetic rats (Streptozotocin, STZ 50 $\mathrm{mg} / \mathrm{kg}$ ) were treated with vehicle or telmisartan $(5 \mathrm{mg} / \mathrm{kg})$ for 8 weeks. Behavioural tests (footprint and hotplate) were performed every 2 weeks after starting treatment. After 4 weeks of treatment, a wound was induced in the right hindlimb of rats and the wound size was measured every 3 days. At the end of the study, animals were sacrificed, blood, serum and hindlimb tissue were separated and used for further analyses.

STZ treated rats showed a decrease in body weight, insulin, adiponectine level and soluble form of receptor of advanced glycation (sRAGE) expression and an increase in glucose, glycated haemoglobin A1c (HbA1c), tumor necrosis factor- $\alpha$ (TNF- $\alpha$ ), advanced glycation end products level (AGEs) and receptor of advanced glycation end products (RAGE) expression compared to control group. This was associated with impaired performance in behavior tests and delayed wound healing. Treatment with telmisartan resulted in significant increase in body weight, serum adiponectin, serum sRAGE level and decreased TNF- $\alpha$, insulin level, serum AGEs and RAGE compared to diabetes. Telmisartan lead to improvement only in gait base and intrastep distance in footprint parameters, while didn't improve hot plate latency or delayed wound healing.

In conclusion, telmisartan may partially improve the deleterious effects of diabetes as peripheral neuropathy through its anti-glycation and anti-inflammatory effects
\end{abstract}

Keywords: Telmisartan, Diabetes, Neuropathy, advanced glycation end products

\section{INTRODUCTION}

Diabetic peripheral neuropathy (DPN) is the most prevalent complication of diabetes and often manifests as a distal, symmetric, sensorimotor neuropathy. More than half of diabetic patients develop DPN (Harati, 2007). Moreover, 15 - 30\% of patients with DPN suffer from painful diabetic neuropathy and the remainder experience a loss of sensation and numbness (Ramos et al., 2007). The clinical symptoms equated with DPN involve poor stride and balance associated with large sensory fibers and abnormal cold and/or heat sensation associated with small sensory fibers. In addition, hyperalgesia, allodynia, paresthesias, and spontaneous pain is associated with diabetes (Gooch \& Podwall, 2004; Edwards et al., 2008). Neuropathic diabetes increases the risk of developing foot ulcers in patients with sensory loss up to seven-fold, compared to nonneuropathic diabetic patients (Wild et al., 2004).

Accumulation of advanced glycation endproduct (AGEs) has been found in healthy aging persons, and this 
accumulation is higher during high glucose concentrations and contributes to microvascular and macrovascular complications in diabetes (LuevanoContreras \& Chapman, 2010). AGEs have been implicated in delayed wound healing associated with diabetes, presumably through vascular, neurological, or intermediary metabolic modifications (Peppa et al., 2009). The deleterious effects of AGEs in different tissues are attributed to their chemical, pro-oxidant, and inflammatory actions (Brownlee et al., 1984; Ahmed, 2005). The biological effects of AGEs are exerted by two different mechanisms: the first is receptorindependent through direct damage of protein structures and extracellular matrix metabolism; and the second is through binding to the receptor for advanced glycation end products (RAGE) (Sheetz \& King, 2002; Ahmed, 2005). AGE-RAGE interaction activates $\mathrm{NAD}(\mathrm{P}) \mathrm{H}$ oxidase leading to intracellular oxidative stress and activation of $\mathrm{NF}-\kappa \mathrm{B}$ (nucler factor kappa beta) (Basta et al., 2005; Lin et al., 2009).

Telmisartan, an angiotensin receptor blocker, is widely used in the treatment of hypertension (Punzi et al., 2013). Telmisartan is the most lipophilic drug of its class and has long half-life after oral administration (approximately 24 hours) (Plosker \& White, 2008). In addition, telmisartan was shown to suppress RAGE expression at both mRNA and protein levels in human cultured microvascular endothelial cells (Yamagishi et al., 2008) and in angiotensin-II-exposed endothelial cells (Nakamura et al., 2005).

Therefore, the aim of the present work was to examine the potentially protective effect of telmisartan in diabetes-induced peripheral neuropathy through its effect on AGEs-RAGE axis.

\section{MATERIALS and METHODS 2.1. Animals}

Adult male albino rats weighing 150-200 g (National research center,
Cairo, Egypt) were housed in clear polypropylene cages (four rats per cage) and kept on a light-dark cycle of equal duration, under standard environmental conditions. Rats were fed commercially available normal pellet diet and water ad libitum. Experimental design and animal handling procedures were approved by the Ethical Committee for Animal Handling at Zagazig University, (ECAHZU) (P1-52014).

\subsection{Drugs and chemicals}

The following drugs and chemicals were used: STZ (Sigma-Aldrich, Dorset, UK), telmisartan (Sigma pharmaceuticals, Egypt), formalin (El-Nasr. Co, Egypt) and dimethyl sulphoxide (DMSO) (Tedia Company Inc., Fairfield, $\mathrm{OH}$ ).

\subsection{Study protocol}

Animals were randomly divided into 3 experimental groups (8 animals each) as follows: control, diabetic and diabetic treated with telmisartan $(5 \mathrm{mg} / \mathrm{kg})$ (Goyal et al., 2011; Zhang et al., 2012). Diabetes was induced by single intraperitoneal (i.p.) +injection of STZ (50 $\mathrm{mg} / \mathrm{kg}$ ) dissolved in ice cold distilled water immediately before use (Reed et al., 1999). The incidence of diabetes was confirmed by measuring blood glucose one week after STZ injection. Animals received tap water and standard diet $(20 \%$ crude protein, $4 \%$ crude fat, $3.5 \%$ crude fiber, $6 \%$ ash, and $0.5 \%$ salt). All drugs were dissolved in dimethyl sulphoxide (DMSO) and treatment started 2 weeks after diabetes induction and continued for 8 weeks. Control and diabetic groups were treated with the vehicle.

\subsection{Behavioural tests:}

The footprint test was used to measure latent motor deficit (Balkaya et al., 2013). Responses of animals in footprint test (stride length, gait base width, stride variability) were measured after 2, 4, 6 and 8 weeks of treatment. 
Tunnel of grey Polyvinyl chloride (PVC) with dimensions: 10x10x50cm, ending in a dark box containing food pellets was used. the floor of the tunnel was covered with white paper (2 DIN A4 sheets jointed with tape).

The rat is taken out of the cage and then fixed like for injection. Then paint forepaws and hind paws with a brush with non-toxic finger paint (for children). The mouse gets a little bit stressed by the handling and because of the unknown environment so that it passes the tunnel without exploring it. The mouse is put at the beginning of the tunnel and moves through it into the box, leaving footprints on the paper. Lift the tunnel and take the mouse out for avoiding it turn around and return. Put the mouse back into the cage.

The following parameters can be measured for the resulted footprint paper:

- Stride length: which mean the distance between two consecutive left or right paw prints

- Gait base of support: mean distance perpendicular to parallel left and right paw prints. This value is determined by measuring the perpendicular distance of a given step to a line connecting its opposite preceding and proceeding steps.

- Stride variability: difference between longest and shortest stride length.

- Intrastep distance: mean distance between alternate left and right paw prints.

For each step parameter, three values are measured from each run, excluding footprints made at the beginning and end of the run where the animal was initiating and finishing movement, respectively. The mean value of each set of three values is used in subsequent analysis.

The hotplate test was used to measure animal response to thermal stimuli every 2 weeks. The surface of a hot plate (XH-2002 premiere slide warmer; Daigger, Vernon Hills, IL) was heated to $50 \pm 0.5$
${ }^{\circ} \mathrm{C}$. The time (in seconds) between the placement of the rats on the plate and the onset of shaking, paw licking, and jumping off the plate was recorded as the response latency. To avoid tissue damage, 50 seconds was set as the cut-off time after which rats were returned to the cage then retested after 20 minutes (Gardmark et al., 1998).

\subsection{Wound induction}

After 4 weeks of treatment (defined as day 0 of wound), each rat was anesthetized with an intraperitoneal injection of thiopental sodium $(50 \mathrm{mg} / \mathrm{kg})$ and a rectangular pattern was marked on the dorsal surface of the right dorsal hindlimb using a flexible transparent plastic template, and then a layer of skin in full thickness with standard area of $2 \mathrm{~mm} \mathrm{x}$ $5 \mathrm{~mm}$ was removed and initial wound size was measured on day 1 then every 3 days till the end of the study (Lau et al., 2009).

\subsection{Biochemical analysis}

At the end of the study (12 $\mathrm{h}$ after the last injection), blood was collected from the retro-orbital plexus and centrifuged $\left(3000 \times \mathrm{g}, 4^{\circ} \mathrm{C}, 20 \mathrm{~min}\right)$ to separate serum that was divided into aliquots and stored at $-20^{\circ} \mathrm{C}$ for biochemical analysis.

Serum glucose was determined by glucose meter (Bionime $\mathrm{GmBH}$ ) using noble metal electrode strips (Bimenya et al., 2003). Glycated hemoglobin (HBA1C) was measured using chromatographic spectrophotometric ion exchange BioSystems S.A. ${ }^{\circledR}$ kits (Costa Brava 30, Barcelona, Spain). Serum insulin level was assayed by sandwich ELISA (Millipore, Cairo, Egypt) (Comitti et al., 1987). Serum tumor necrosis factor- $\alpha$. (TNF- $\alpha$ ) level was determined by ELISA using Quantikine ${ }^{\circledR}$ kit (R\&D systems, Cairo, Egypt) (Maskos et al., 1998). Serum adiponectin level was assayed using $\mathrm{CHEMICON}{ }^{\circledR}$ rat adiponectin ELISA kit (Chemicon International, Temecula, CA, USA) (Huang et al., 2009). 
Serum AGEs level was assayed using MyBioSource MBS700464 rat AGE ELISA kit according to the manufacturer's instructions. Rat serum RAGE was assayed using RayBio ${ }^{\circledR}$ Rat RAGE ELISA kit (RayBiotech, Inc., Norcross, GA, USA) (Nirala et al., 2015). Rat serum soluble receptor of advanced glycation endproduct (sRAGE) was assayed by AVISCERA BIOSCIENCE® ELISA kit (Santa Clara, CA, USA) according to the manufacturer's instructions.

\subsection{Complete blood count}

Complete blood count was determined using automated haematology analyser (Sysmex Ame rica Inc., Lincolnshire, IL60069, USA) 3 part differentiation and the following parameters were determined: haemoglobin (HGB), mean corpuscular haemoglobin $(\mathrm{MCH})$, mean corpuscular haemoglobin concentration (MCHC), red blood cell (RBC), mean corpuscular volume (MCV), haematocrit (HCT), red cell distribution width percentage (RDW\%), platelet count (PLT), mean platelet volume (MPV), platelet distribution width (PDW), plateletcrit (PCT), white blood cell (WBC), lymphocyte (LYM), granulocyte (GRAN), minimum inhibitory dilution (MID).

\subsection{Statistical analysis}

Statistical analysis was carried out using GraphPad Prism 5.0 ${ }^{\circledR}$ (Graphpad Software, La Jolla; CA; USA). Results were expressed as the mean \pm standard error of the mean (mean \pm SEM). One-way analysis of variance (ANOVA) was used for multiple comparison between groups followed by Newman-Keul's post hoc test with levels of significance; $p<0.05, p<0.01$ and $p<0.001$. Two-way ANOVA followed by Bonferroni post hoc was used to compare statistical difference in behavioural experiments and wound healing.

\section{RESULTS}

3.1 Effect of diabetes and treatment with telmisartan on body weight, blood glucose, glycated hemoglobin and insulin levels:

Diabetes resulted in a significant decrease in body weight to reach $111 \pm 5.78$ vs $203 \pm 4.63 \mathrm{~g}$ compared to control group, while administration of telmisartan to diadetic animals resulted in significant increase in body weight reaching $154 \pm 4$ vs $111 \pm 5.78 \mathrm{~g}$ compared to diabetic group (Figure 1(a)).

Diabetes resulted in a significant increase in blood glucose reaching $404.5 \pm 37.53$ vs $105.5 \pm 4.92 \mathrm{mg} / \mathrm{dl}$ compared to control group, while administration of telmisartan to diabetic animals didn't result in significant change in blood glucose compared to diabetic group as shown in figure 1(b).

Diabetes resulted in a significant decrease in insulin level reaching $3.5 \pm 0.25$ vs $15 \pm 1.03 \mu \mathrm{g} / 1$ compared to control group, while administration of telmisartan to diabetic animals didn't result in significant change in insulin level compared to diabetic group (Figure 1c).

Figure 1(d) showed that diabetes resulted in a significant increase in $\mathrm{hbA1C}$ reaching $13.5 \pm 0.09$ vs $5.2 \pm 0.24 \%$ compared to control group, while administration of telmisartan to diabetic animals didn't result in significant change in $\mathrm{HbA} 1 \mathrm{C}$ compared to diabetic group

\subsection{Effect of diabetes and treatment with} telmisartan on wound healing:

Diabetes resulted in delayed wound healing on days $5,9,13,17,21,25,29$ reaching $89.7 \pm 2, \quad 81.8 \pm 1.63, \quad 76.5 \pm 1.46$, $66.2 \pm 1.22, \quad 56.7 \pm 1.50, \quad 40.3 \pm 1.13$ and $33.5 \pm 0.90 \quad$ vs $50 \pm 1.6, \quad 33.1 \pm 1.58$, $21.3 \pm 1.05,14.8 \pm 0.78,12.6 \pm 0.53,8.8 \pm 0.47$ and $4.2 \pm 0.25 \mathrm{~mm}^{2}$ compared to control group. For telmisartan; improvement in wound healing was observed only on days 5 and 13 reaching $83 \pm 1.85$ and $68.7 \pm 1.22$ vs $89.7 \pm 2,76.5 \pm 1.46 \mathrm{~mm}^{2}$ respectively compared to diabetic group (Figure 2 a). 


\subsection{Effect of diabetes and treatment with telmisartan on hotplate test:}

Diabetic

showed a significant decrease in hotplate latency time after 2, 4, 6 and 8 weeks of treatment reaching $9.5 \pm 1.19,6.3 \pm 1.11,7.2 \pm 0.83$ and
$5.6 \pm 0.61$ sec vs $46.5 \pm 1.08,43.8 \pm 1.04$, $43.2 \pm 1.30$ and $44.2 \pm 1.35 \mathrm{sec}$ respectively compared to control group. While telmisartan didn't result in any significant change in hotplate latency compared to diabetic group (Figure 2b).

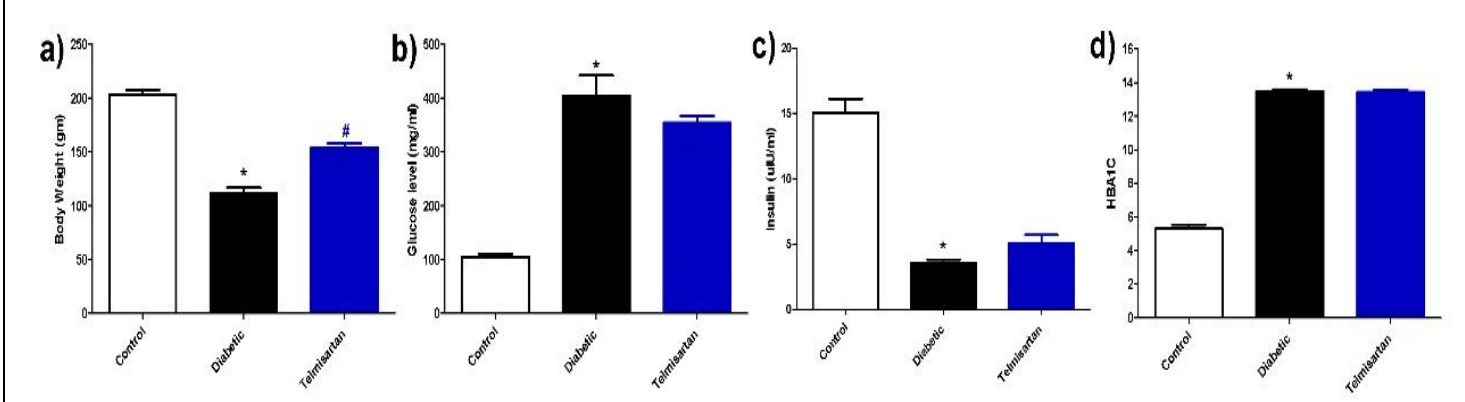

Figure 1: Effect of diabetes induction using STZ $(50 \mathrm{mg} / \mathrm{kg})$ and treatment with telmisartan $(5 \mathrm{mg} / \mathrm{kg})$ for 8 weeks on: a) body weight, b) blood glucose, c) serum insulin and d) Glycated hemoglobin (HBA1c). Data are presented as mean \pm SEM (n = 6-8); \%, @ ${ }^{*}$ significantly different from the corresponding control group at $\mathrm{P}<0.05$, $\mathrm{P}<0.01, \mathrm{P}<0.001,{ }^{\&}, \$$, \# significantly different from diabetic group at $\mathrm{P}<0.05, \mathrm{P}<0.01$, $\mathrm{P}<0.001$ using One Way ANOVA and Newman Keuls post hoc test.

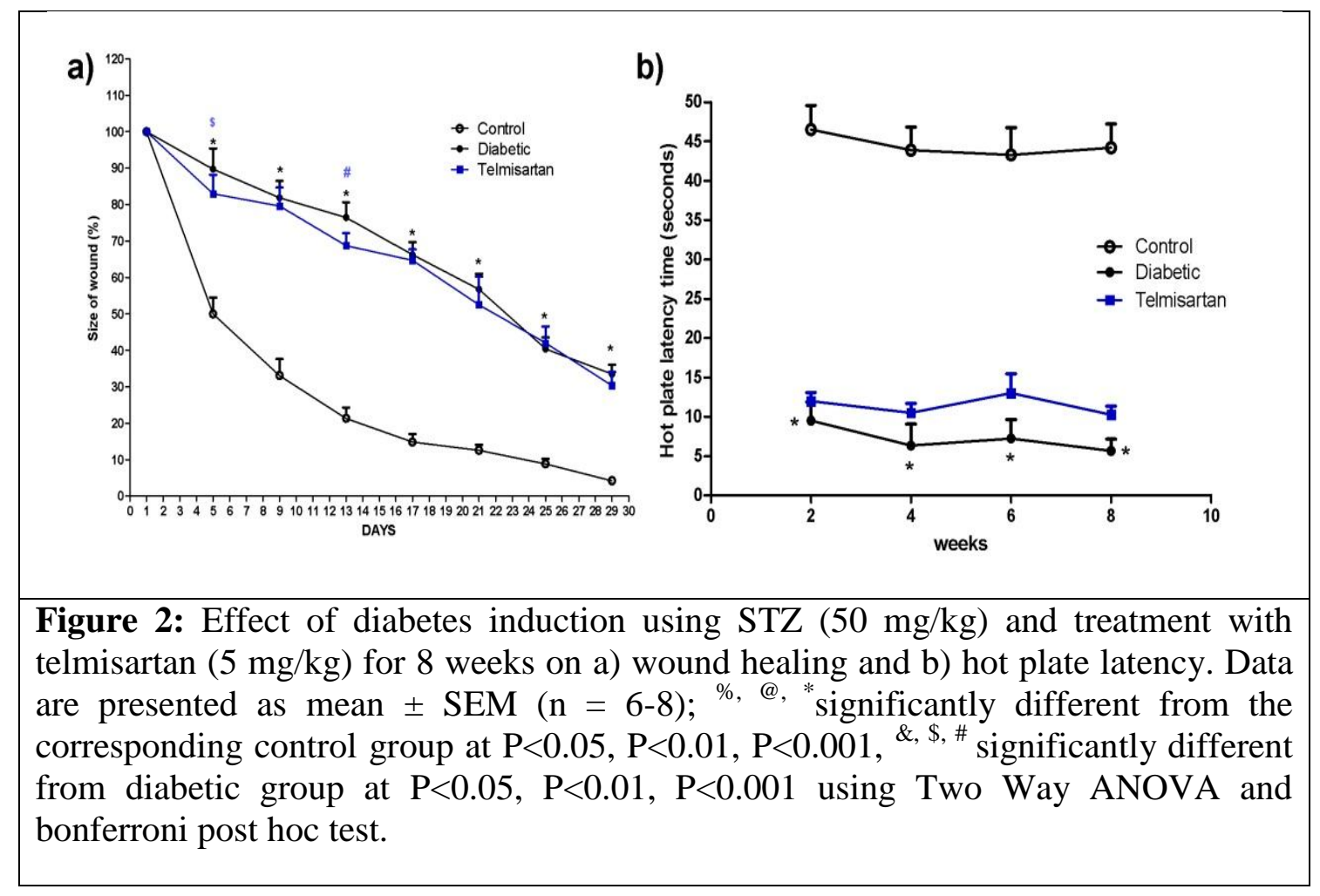


Zagazig J. Pharm. Sci. June, 2018

Vol. 27, Issue 1, pp. 39- 56

\subsection{Effect of diabetes and treatment with telmisartan on foot print test:}

Diabetes resulted in a significant decrease in gait base after 2, 4, 6 and 8 weeks of treatment reaching $2.1 \pm 0.21$, $2.1 \pm 0.15, \quad 2.5 \pm 0.15$ and $2.6 \pm 0.20$ vs $3.6 \pm 0.19,3.6 \pm 0.23,3.6 \pm 0.24$ and $3.9 \pm 0.19$ $\mathrm{cm}$ respectively compared to control group, while administration of telmisartan to diabetic animals resulted in significant increase in gait base after 2, 4, 6 and 8 weeks reaching $3.7 \pm 0.10,3.7 \pm 0.20$, $3.6 \pm 0.21$ and $3.5 \pm 0.24$ vs. $2.1 \pm 0.21$, $2.1 \pm 0.15,2.5 \pm 0.15$ and $2.6 \pm 0.20 \mathrm{~cm}$ respectively compared to diabetic group (Figure 3 a).

Diabetes resulted in a significant decrease in intrastep distance after 2, 4, 6, 8 weeks of treatment reaching $4 \pm 0.18$, $4.3 \pm 0.26, \quad 4.4 \pm 0.30$ and $4.8 \pm 0.31$ vs $6.7 \pm 0.16,7 \pm 0.34,7.2 \pm 0.23$ and $7.3 \pm 0.31$ $\mathrm{cm}$ respectively compared to control group. While administration of telmisartan to diabetic animals resulted in significant increase in intrastep distance after 2, 4, 6 and 8 weeks compared to diabetic group reaching $6.8 \pm 0.40,6.6 \pm 0.31,6.5 \pm 0.37$ and $6.6 \pm 0.55$ vs. $4 \pm 0.18,4.3 \pm 0.26,4.4 \pm 0.30$ and $4.8 \pm 0.31 \mathrm{~cm}$ for diabetic group respectively as shown in figure 3 (b).

Induction of diabetes resulted in significant decrease in left stride length after 2, 4, 6 and 8 weeks of treatment reaching $12.1 \pm 0.17,12.1 \pm 0.20,12.1 \pm 0.22$ and $11.8 \pm 0.10$ vs $13.2 \pm 0.17,13.2 \pm 0.14$, $13.4 \pm 0.23$ and $13.4 \pm 0.16 \mathrm{~cm}$ respectively compared to control group. While telmisartan failed to change the left stride length compared to diabetic group (Figure $3 \mathrm{c})$.

Figure 3 (d) showed that diabetes resulted in a significant decrease in right stride length after 2, 4, 6 and 8 weeks of treatment reaching $10.7 \pm 0.23,11.1 \pm 0.21$, $11.3 \pm 0.26$ and $11.4 \pm 0.29$ vs $11.7 \pm 0.17$
ISSN 1110-5089

ISSN (on-line) 2356_9786

$12.2 \pm 0.19,12.4 \pm 0.23$ and $12.6 \pm 0.27 \mathrm{~cm}$ respectively compared to control group. On the other hand, telmisartan has no significant effect on right stride length compared to diabetic group.

Diabetes resulted in a significant decrease in left stride variability after 2, 4, 6 and 8 weeks of treatment reaching $1.4 \pm 0.13$, $1.6 \pm 0.13, \quad 1.7 \pm 0.20$ and $2.2 \pm 0.19$ vs $4.2 \pm 0.27,4.4 \pm 0.41,4.4 \pm 0.20$ and $4.4 \pm 0.08$ $\mathrm{cm}$ respectively compared to control group, while administration of telmisartan showed no significant change on left stride variability compared to diabetic group as shown in figure 3 (e).

Figure 3 (f) revealed that diabetes resulted in a significant decrease in right stride variability after $2,4,6$ and 8 weeks of treatment reaching $2.2 \pm 0.28, \quad 1.8 \pm 0.21$, $1.7 \pm 0.18$ and $1.9 \pm 0.13$ vs $4.8 \pm 0.11$, $4.5 \pm 0.26, \quad 4.6 \pm 0.23$ and $4.7 \pm 0.15 \mathrm{~cm}$ respectively compared to control group, while administration of telmisartan showed no significant change on left stride variability compared to diabetic group.

\subsection{Effect of diabetes and treatment with telmisartan on inflammatory cytokines:}

STZ-induced diabetes resulted in significant increase in TNF- $\alpha$ level compared to control group (155.8 vs 29.7 $\mu \mathrm{g} / \mathrm{l})$, while administration of telmisartan to diabetic animals resulted in significant decrease in TNF- $\alpha$ level reaching 86 vs $155.8 \mu \mathrm{g} / \mathrm{l}$ respectively compared to diabetic group (figure 4(a)).

Diabetes induction resulted in significant decrease in serum adiponectin level reaching 3.6 vs $12.2 \mathrm{ng} / \mathrm{ml}$ compared to control group. Telmisartan resulted in significant increase in serum adiponectin level reaching 8.2 vs $3.6 \mathrm{ng} / \mathrm{ml}$ respectively compared to diabetic group (figure $4 \mathrm{~b}$ ). 

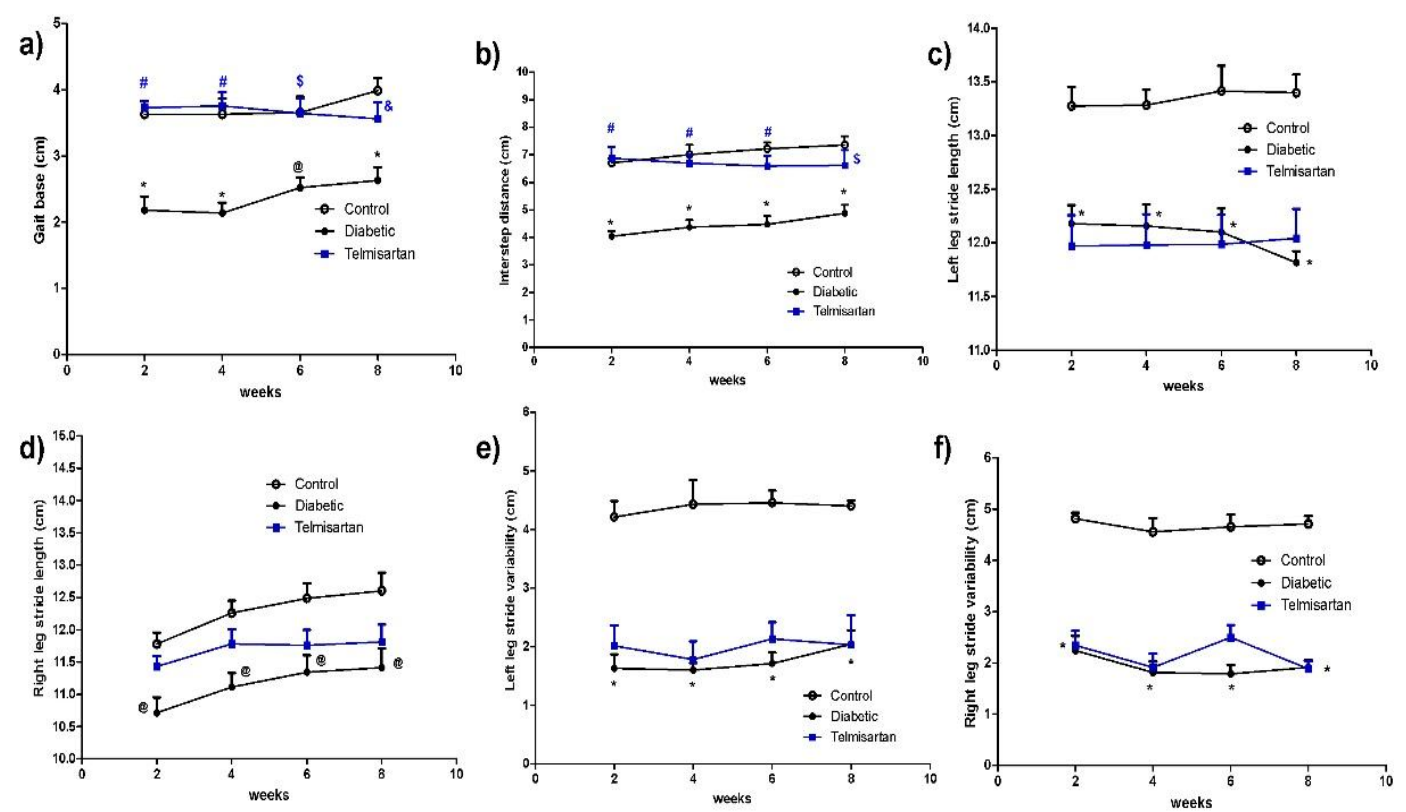

Figure 3: Effect of diabetes induction using STZ $(50 \mathrm{mg} / \mathrm{kg})$ and treatment with telmisartan $(5 \mathrm{mg} / \mathrm{kg})$ for 8 weeks on footprint parameters: a) gait base, b) intrastep distance, c) left leg stride length, d) right leg stride length, e) left leg stride variability and f) right leg stride variability. Data are presented as mean \pm SEM $(n=6-8)$; $\%$, * significantly different from the corresponding control group at $\mathrm{P}<0.05, \mathrm{P}<0.01$, $\mathrm{P}<0.001,{ }^{\&, \$, ~ \# ~ s i g n i f i c a n t l y ~ d i f f e r e n t ~ f r o m ~ d i a b e t i c ~ g r o u p ~ a t ~} \mathrm{P}<0.05, \mathrm{P}<0.01, \mathrm{P}<0.001$ using Two Way ANOVA and bonferroni post hoc test.
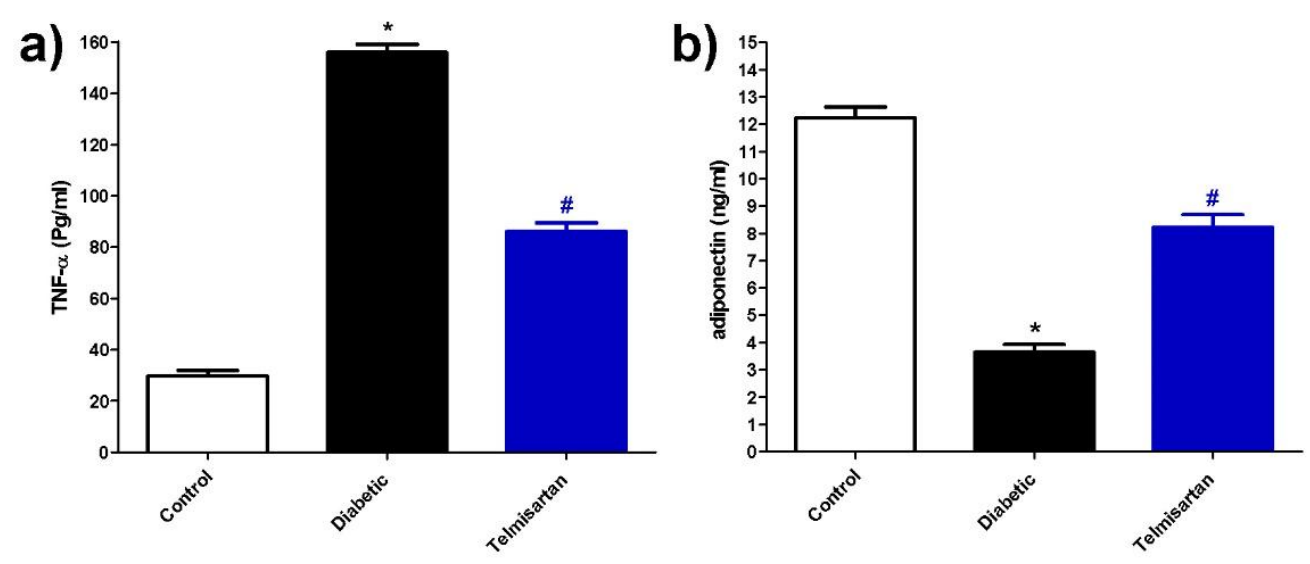

Figure 4: Effect of diabetes induction using STZ $(50 \mathrm{mg} / \mathrm{kg})$ and treatment with telmisartan $(5 \mathrm{mg} / \mathrm{kg})$ for 8 weeks on: a) serum TNF- $\alpha$ and b) serum adiponectin levels. TNF- $\alpha$, tumor necrosis factor- $\alpha$. Data are presented as mean \pm SEM $(n=6-8)$;

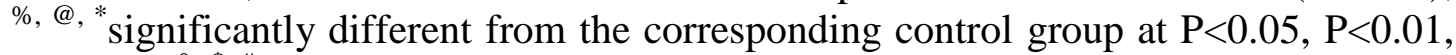
$\mathrm{P}<0.001,{ }^{\&}, \$$, \# significantly different from diabetic group at $\mathrm{P}<0.05, \mathrm{P}<0.01, \mathrm{P}<0.001$ using One Way ANOVA and Newman Keuls post hoc test. 


\subsection{Effect of diabetes and treatment with telmisartan on serum AGEs, RAGE and SRAGE:}

In figure 5 (a), diabetes resulted in a significant increase in AGEs level reaching $46.5 \pm 0.80$ vs $9.1 \pm 0.87 \mu \mathrm{g} / \mathrm{ml}$ compared to control group, while administration of telmisartan to diabetic animals resulted in significant decrease in AGEs level reaching $32.8 \pm 1.18$ vs $46.5 \pm 0.80 \mu \mathrm{g} / \mathrm{ml}$ respectively compared to diabetic group.

Diabetes induction resulted in a significant increase in RAGE level compared to control group $172.6 \pm 2.99$ vs $56.92 \pm 6.95$ $\mathrm{Pg} / \mathrm{ml}$. On the other hand, administration of telmisartan to diabetic animals resulted in significant decrease in RAGE level reaching $132.9 \pm 6.59$ vs $172.6 \pm 2.99 \mathrm{Pg} / \mathrm{ml}$ respectively compared to diabetic group as shown in figure $5(\mathrm{~b})$.
Diabetes resulted in a significant decrease in sRAGE level reaching $28.1 \pm 3.26$ vs $52 \pm 4.96 \mu \mathrm{g} / 1$ compared to control group. Treatment with telmisartan resulted in significant increase in sRAGE level reaching $43.9 \pm 5.22$ vs $28.1 \pm 3.26 \mu \mathrm{g} / 1$ respectively compared to diabetic group as shown in figure 5 (c).

\subsection{Effect of diabetes and treatment with telmisartan on complete blood count:}

Table (1) shows that diabetes resulted in a significant decrease in HGB level reaching 10 vs $13.2 \mathrm{~g} / \mathrm{dl}$ compared to control group, while administration of telmisartan to diabetic animals resulted in significant increase in HGB level reaching 13.2 vs $10 \mathrm{~g} / \mathrm{dl}$ respectively compared to diabetic group.

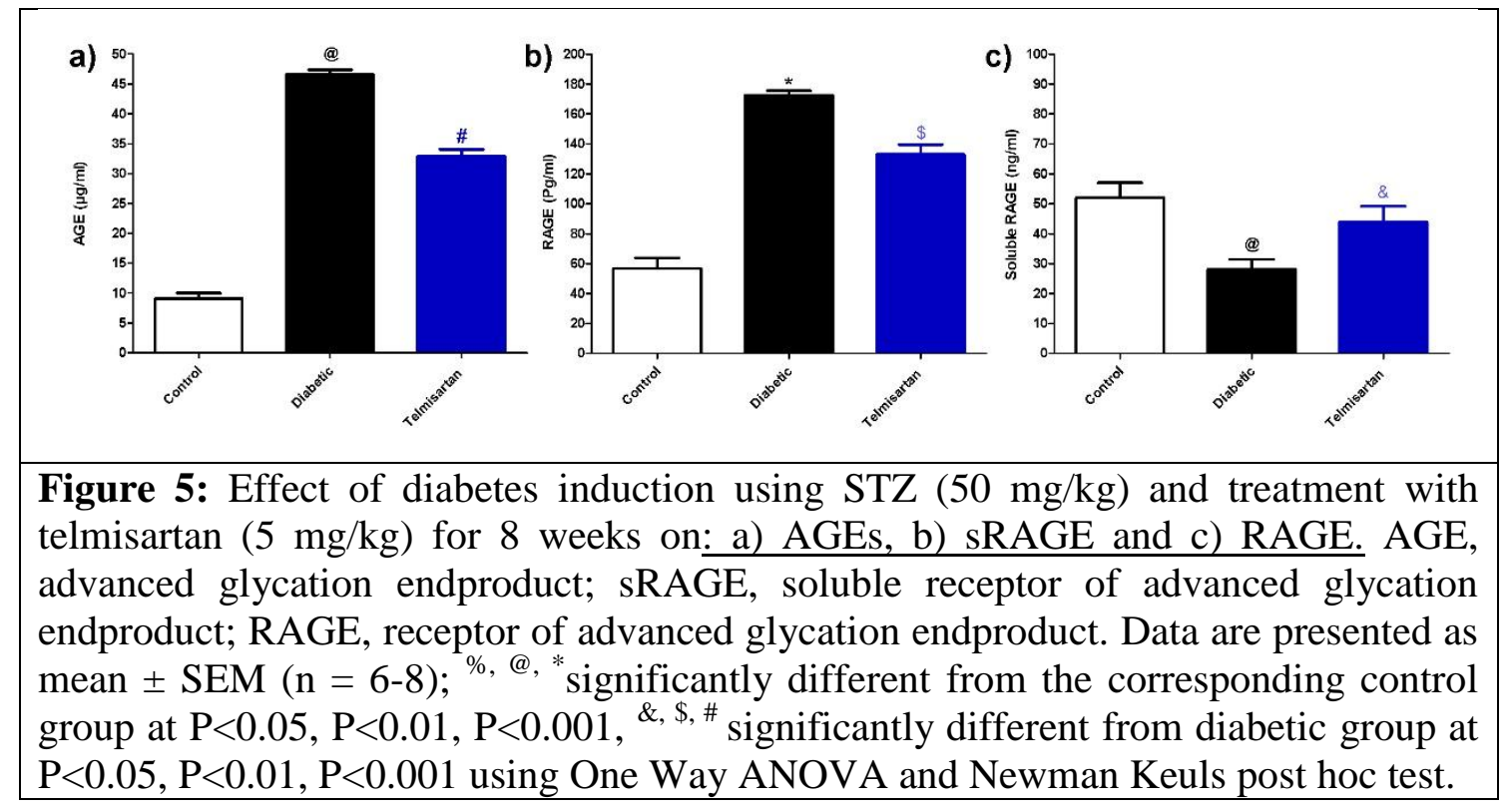

Diabetes resulted in a significant decrease in $\mathrm{MCH}$ level reaching 24.7 vs $40.1 \mathrm{pg}$ compared to control group, while administration of telmisartan to diabetic animals resulted in significant increase in MCH level reaching 38.2 vs 24.7 pg respectively compared to diabetic group as shown in table 1.

Diabetes resulted in a significant decrease in MCHC level reaching 16 vs $18.7 \mathrm{~g} / \mathrm{dl}$ compared to control group. Treatment with telmisartan lead to significant increase in MCHC level reaching 18.4 vs $16 \mathrm{~g} / \mathrm{dl}$ respectively compared to diabetic group (Table 1).

$$
\text { Table } 1 \text { shows that }
$$
diabetes resulted in a significant increase in RBCs level compared to control group reaching 8.9 vs $6.7 \times 10^{12} / \mathrm{L}$. Telmisartan administration to diabetic animals resulted in significant decrease in RBC level 7.2 vs 
$8.9 \times 10^{12} / \mathrm{L}$ respectively compared to diabetic group.

Diabetes resulted in a significant increase in MCV level reaching 54.4 vs $46.7 \mathrm{fl}$ compared to control group. While, administration of telmisartan to diabetic animals resulted in significant decrease in MCV level reaching 48.3 vs $54.4 \mathrm{fl}$ respectively compared to diabetic group (table 1).

Table 1 shows that STZ-induced diabetes resulted in a significant increase in HCT level reaching 42.6 vs $33 \%$

Table 1: Effect of telmisartan $\left(5 \mathrm{mg} \cdot \mathrm{kg}^{-1}\right)$ on $\mathrm{HGB}, \mathrm{MCH}, \mathrm{MCHC}, \mathrm{RBC}, \mathrm{MCV}, \mathrm{HCT}$ and RDW\% in diabetes.

\begin{tabular}{lccccccc}
\hline Treatment & HGB & MCH & MCHC & RBC & MCV & HCT & RDW\% \\
& $\mathrm{g} / \mathrm{dl}$ & $\mathrm{pg}$ & $\mathrm{g} / \mathrm{dl}$ & $10^{12} / \mathrm{L}$ & $\mathrm{Fl}$ & $\%$ & $\%$ \\
\hline Control & $13.22 \pm$ & $40.10 \pm$ & $18.74 \pm$ & $6.73 \pm$ & $46.74 \pm$ & $33.04 \pm$ & $12.56 \pm$ \\
& 0.79 & 0.32 & 0.18 & 0.28 & 0.61 & 2.137 & 0.13 \\
Diabetic & $10.02 \pm$ & $24.72 \pm$ & $16.06 \pm$ & $8.98 \pm$ & $54.4 \pm$ & $42.64 \pm$ & $14.12 \pm$ \\
& $0.98^{\%}$ & $1.93^{*}$ & $0.83^{\%}$ & $0.21^{\%}$ & $2.65^{\%}$ & $1.32^{\%}$ & $0.3^{\%}$ \\
Telmisartan & $13.26 \pm$ & $38.2 \pm$ & $18.44 \pm$ & $7.23 \pm$ & $48.34 \pm$ & $34.92 \pm$ & $12.40 \pm$ \\
& $1.022^{\&}$ & $0.58^{\#}$ & $0.44^{\&}$ & $0.64^{\&}$ & $0.92^{\&}$ & $3.08^{\&}$ & $0.25^{\&}$ \\
\hline
\end{tabular}

${ }^{\%} \mathrm{P}<0.05,{ }^{@} \mathrm{P}<0.01, * \mathrm{P}<0.001$, compared with the corresponding control group values;

${ }^{\&} \mathrm{P}<0.05,{ }^{\$} \mathrm{P}<0.01,{ }^{\#} \mathrm{P}<0.001$ compared with the corresponding diabetes group values; by One

Way ANOVA and Newman Keuls post hoc test

Table 2 shows that diabetes resulted in a significant decrease in PLT number reaching 115.2 vs $296 \times 10^{9} / \mathrm{L}$ compared to control group. On the other hand, administration of telmisartan to diabetic animals resulted in significant increase in PLT number reaching 452.6 vs $115.2 \mathrm{x}$ $10^{9} / \mathrm{L}$ respectively compared to diabetic group.

Induction of diabetes resulted in a significant increase in MPV level reaching 6.9 vs $5.7 \mathrm{fl}$ compared to control group, while administration of telmisartan to diabetic animals resulted in significant decrease in MPV level reaching 5.9 vs 6.9 fl respectively compared to diabetic group as shown in table 2 . compared to control group, while administration of telmisartan to diabetic animals resulted in significant decrease in HCT level reaching 34.9 vs $42.6 \%$ respectively compared to diabetic group.

Diabetes resulted in a significant increase in RDW\% reaching 14.1 vs $12.5 \%$ compared to control group. Administration of telmisartan to diabetic animals resulted in significant decrease in RDW\% reaching 12.4 vs $14.1 \%$ compared to diabetic group as shown in table 1 . 
Table 2: Effect of telmisartan $\left(5 \mathrm{mg} \mathrm{kg}^{-1}\right)$ on PLT, MPV, PDW and PCT in diabetes.

\begin{tabular}{lcccc}
\hline Treatment & PLT & MPV & PDW & PCT \\
& $10^{9} / \mathrm{L}$ & Fl & fl & $\%$ \\
\hline Control & $296.0 \pm 28.33$ & $5.78 \pm 0.1$ & $8.58 \pm 0.1$ & $0.36 \pm 0.02$ \\
Diabetic & $115.2 \pm 7.41^{*}$ & $6.94 \pm 0.24^{\%}$ & $9.94 \pm 0.25^{@}$ & $0.54 \pm 0.01^{\%}$ \\
Telmisartan & $452.6 \pm 27.85^{\#}$ & $5.98 \pm 0.22^{\&}$ & $8.22 \pm 0.32^{\#}$ & $0.26 \pm 0.02^{\#}$ \\
\hline
\end{tabular}

${ }^{\%} \mathrm{P}<0.05,{ }^{@} \mathrm{P}<0.01, * \mathrm{P}<0.001$, compared with the corresponding control group values;

${ }^{\&} \mathrm{P}<0.05,{ }^{\$} \mathrm{P}<0.01,{ }^{\#} \mathrm{P}<0.001$ compared with the corresponding diabetes group values; by One Way ANOVA and Newman Keuls post hoc test

Diabetes resulted in a significant increase in WBC level reaching 12.2 vs $10.2 \mathrm{x}$ $10^{9} / \mathrm{L}$ compared to control group, while administration of telmisartan to diabetic animals resulted in significant decrease in WBC level reaching 8.4 vs $12.2 \times 10^{9} / \mathrm{L}$ respectively compared to diabetic group (Table 3).

Diabetes resulted in a significant increase in GRAN level reaching 3.1 vs $1.5 \times 10^{9} / \mathrm{L}$ compared to control group, while administration of telmisartan to diabetic animals resulted in significant decrease in GRAN level reaching 1.1 vs $3.1 \times 10^{9} / \mathrm{L}$ respectively compared to diabetic group (Table 3).

Diabetes induction resulted in a significant increase in MID level reaching 2.1 vs $1.7 \mathrm{x}$ $10^{9} / \mathrm{L}$ compared to control group, while administration of telmisartan to diabetic animals resulted in significant decrease in MID level reaching 1.3 vs $2.1 \times 10^{9} / \mathrm{L}$ respectively compared to diabetic group (Table 3).

Table 3: Effect of telmisartan $\left(5 \mathrm{mg} \cdot \mathrm{kg}^{-1}\right)$ on WBC, LYM, GRAN and MID in diabetes.

\begin{tabular}{lcccc}
\hline \hline Treatment & WBC & LYM & GRAN & MID \\
& $10^{9} / \mathrm{L}$ & $10^{9} / \mathrm{L}$ & $10^{9} / \mathrm{L}$ & $10^{9} / \mathrm{L}$ \\
\hline Control & $10.25 \pm 0.59$ & $7.38 \pm 0.28$ & $1.5 \pm 0.14$ & $1.76 \pm 0.09$ \\
Diabetic & $12.22 \pm 0.3^{(}$ & $3.92 \pm 0.24^{*}$ & $3.12 \pm 0.27^{*}$ & $2.16 \pm 0.11^{\%}$ \\
Telmisartan & $8.4 \pm 0.65^{\#}$ & $5.1 \pm 0.38$ & $1.12 \pm 0.12^{\#}$ & $1.30 \pm 0.12^{\#}$ \\
\hline
\end{tabular}

${ }^{\%} \mathrm{P}<0.05,{ }^{@} \mathrm{P}<0.01, * \mathrm{P}<0.001$, compared with the corresponding control group values;

${ }^{\&} \mathrm{P}<0.05,{ }^{\$} \mathrm{P}<0.01,{ }^{\#} \mathrm{P}<0.001$ compared with the corresponding diabetes group values; by One Way ANOVA and Newman Keuls post hoc test.

\section{DISCUSSION}

The aim of the present work was to investigate the potentially protective effect of telmisartan, an angiotensin receptor blocker, on diabetes-induced peripheral neuropathy in rats.

Our data conclusively showed that telmisartan partially improved diabetic neuropathy in rats as evidenced by improving some foot print parameters but lacked beneficial effects on delayed wound healing. The effect of telmisartan might be partly attributed to its anti-inflammatory effects.

Streptozotocin, STZ, is well known to cause damage of pancreatic $\beta$-cells
(Szkudelski, 2001; Lenzen, 2008). STZdiabetic rat model reliably produces many of the signs and symptoms of human diabetes, in particular diastolic cardiac dysfunction, cataracts and neuropathy (Wei et al., 2003). In rats, it has been reported that a dose ranging from 25 to $100 \mathrm{mg} / \mathrm{kg}$ STZ was successful in inducing a dose dependent hyperglycemia (Hayashi et al., 2006). In the present study, intraperitoneal injection of single dose of STZ $(50 \mathrm{mg} / \mathrm{kg}$ ) developed significant increase in blood glucose level and significant decrease in serum insulin level as previously described by Hassan et al., (2014). 
Measurement of HBA1C in patients with diabetes is accepted as a standard for assessment of glycemic control and is a critical element in clinical practice (Lester, 1989). The three parameters, glucose, HBA1C and insulin play fundamental roles in the pathogenesis of diabetes depending on their levels in circulation (George et al., 2013). In this work, diabetes was associated with elevation of HBA1C. This is consistent with previous work where diabetes induction with STZ for 8 weeks raised HBA1C level (Huang et al., 2003). Telmisartan didn't affect either blood glucose or insulin or HBA1C levels.

Altered glucose homeostasis and persistent hyperglycemia in diabetes lead to AGEs accumulation which are primarily responsible for the damage of cells that have a slow turn over (like neuronal tissue) (Mishra et al., 2008). In the present study, diabetes was associated with elevated serum levels of AGEs, RAGE and a reduction in sRAGE level. Diabetes was previously shown to be associated with higher levels of AGEs (Tanaka et al., 1999) and RAGE (Kislinger et al., 2001) and reduced sRAGE levels (Norata et al., 2009; Devangelio et al., 2007). Telmisartan administration in the present study resulted in reduction of serum levels of AGEs and RAGE and increased sRAGE compared to diabetes. Previously, telmisartan suppressed RAGE expression at both mRNA and protein levels in human cultured microvascular endothelial cells (Yamagishi et al., 2008).

Previous studies have clearly shown that failure of foot ulcer healing can eventually lead to amputation, therefore, diagnosis and treatment of ulcers should be both timely and effective (McLennan et al., 2006). In the present study, diabetes was associated with delayed wound healing which is in consistence with the study carried out by Tong et al., 2012 in which diabetes induction by STZ in rats showed slow rate of healing of the ulcer made on the dorsal skin. While, treatment with telmisartan caused initial improvement in wound healing after 5 days of wound induction but this improvement started to disappear starting from the $9^{\text {th }}$ day post-injury.

Peripheral neuropathy may be asymptomatic, or symptomatic, they may be negative or positive. Negative symptoms include loss of sensation and loss of strength, while positive symptoms include pricking or pain (Davies et al., 2006). Chronic painful diabetic peripheral neuropathy can cause symptoms that last for years and severely impair quality of life (Benbow et al., 1998). Diabetic animals in this study showed elevated thermal hyperalgesia in hotplate test and this is in agreement with previous study of Sharma et al., 2006. In this study, telmisartan didn't prevent thermal hyperalgesia in diabetic animals which is in accordance with the result of Al-Rejaie et al. (2015) in which telmisartan failed to inhibit thermal hyperalgesia in a diabetic neuropathic pain model in wistar rats but improved mechanical hyperalgesia using RandallSelitto test.

Walking capacity and performance decrease with progression of foot complications (Kanade et al., 2006). The footprint test is designed to measure latent motor deficit. It has already been used for detection of ataxia in Huntington disease (Balkaya et al., 2013). In the current study, diabetic rats revealed significant change in foot print parameters. People with diabetic peripheral neuropathy are known to present with a slower gait pattern (Menz et al., 2004). Telmisartan administration improved gait base and intrastep distance only. This is the first study to examine the effect of telmisartan on footprint.

The initiation of the pain process during diabetic neuropathy is mediated through proinflammatory cytokines, such as TNF- $\alpha$ that is released from activated microglia (Zychowska et al., 2013), while adiponectin secreted by adipose tissue possess insulin-sensitizing, antiinflammatory and antioxidant properties 
(Balsan et al., 2015). Low plasma adiponectin levels, might contribute to diabetic and pre-diabetic peripheral and central neuropathy, respectively (Anderson et al., 2014). In the present work, diabetes was associated with raised level of TNF- $\alpha$ and low level of adiponectin is in consistence with the previous study of Tsunekawa et al., 2003. Telmisartan administration reduced the level of TNF- $\alpha$ and raised the level of adiponectin but still significantly different from control group. The present results are also in agreement with the findings reported by Guo et al., 2016 in which the expression of adiponectin and its receptors were upregulated in the testis of STZ-induced diabetic rats after telmisartan treatment.

Diabetic animals in the present study showed an increased HCT which is in consistence with previous study of Tulloch-Reid et al., 2004 in which the level of HCT was associated with higher risk of developing type 2 diabetes. Increasing HCT value is considered to be potentially pathological as shown by the study of Danesh et al. (2000), who found that high hematocrit increases cardiovascular risk. Abnormal increase in the size of red blood cells as indicated by increased MCV accompanied with decrease in both $\mathrm{MCH}$ and $\mathrm{MCHC}$ and increase in RDW\% were observed in the present study. Similar results were previously reported (Morse et al., 1981; Hardikar et al., 2012).

Platelets secrete components of the blood coagulation pathway and growth factors necessary for wound healing (Vinik et al., 2001). In the present study, PLT count decreased while, MPV, PDW and PCT levels were significantly increased which is in harmony with previous studies (Demirtas et al., 2015; Yeom et al., 2016). Shortened platelet survival in the diabetic rat is caused initially by a platelet defect (Winocour et al., 1984). The increased platelet activity may play a role in the development of vascular complications of this metabolic disorder. MPV is an indicator of the average size and activity of platelets. Larger platelets are younger and exhibit more activity (Kodiatte et al., 2012) because of elevated prothrombic contents, such as thromboxane A2, thromboxane B2, platelet factor 4, serotonin, and plateletderived growth factor (Gasparyan et al., 2011). As with MPV, increased PDW and PCT are also reported to be associated with diabetes and vascular complications (Davi \& Patrono, 2007; Demirtas et al., 2015).

Elevated WBC count, an indicator of chronic inflammation, is associated with both macro- and microvascular complications in type 2 diabetes (Tong et al., 2004). In the present study, overall WBC count was elevated in diabetic group. GRAN and MID count was elevated but LYM count was decreased significantly compared to control group. The results of the current study are consistent with previous studies (Turner et al., 1994; Woo et al., 2011; Mahmoud, 2013). Reduced number of blood-circulating lymphocytes was previously found in diabetic patients which is attributed to high occurrence of apoptosis in lymphocytes (Otton et al., 2004).

Telmisartan restored normal level of $\mathrm{HGB}, \mathrm{MCH}, \mathrm{MCHC}, \mathrm{RBC}, \mathrm{MCV}$, HCT, RDW\%, MPV, PDW, PCT, GRAN and MID but significantly increased the level of PLT and decreased WBC compared to diabetic group but still significantly different from control group. On the other hand, telmisartan didn't affect the level of LYM. Telmisartan was previously shown to lower the level of WBCs in animal model of airways inflammation (Hussain et al., 2014).

\section{Conclusion}

Our results have revealed that targeting AGEs by telmisartan which act by reducing level of AGEs and its receptor RAGE and increasing sRAGE level was partially effective against diabetic neuropathy but ineffective against improving delayed wound healing in 
diabetes in the tested dose, however further research is needed to test dose dependency or the effect of longer treatment period on wound healing.

\section{REFERENCES}

Ahmed N. (2005) Advanced glycation endproducts--role in pathology of diabetic complications. Diabetes Res Clin Pract, 67: 3-21.

Al-Rejaie S.S., Abuohashish H.M., Ahmed M.M., Arrejaie A.S., Aleisa A.M. and AlSharari S.D. (2015) Telmisartan inhibits hyperalgesia and inflammatory progression in a diabetic neuropathic pain model of Wistar rats. Neurosciences, 20: 115123.

Anderson N.J., King M.R., Delbruck L. and Jolivalt C.G. (2014) Role of insulin signaling impairment, adiponectin and dyslipidemia in peripheral and central neuropathy in mice. Dis Model Mech, 7: 625-633.

Balkaya M., ber J.M., Rex A. and Endres M. (2013) Assessing PostStroke Behavior in Mouse Models of Focal Ischemia. J Cereb Blood Flow Metab, 33: 330-338.

Balsan G.A., Vieira J.L., Oliveira A.M. and Portal V.L. (2015) Relationship between adiponectin, obesity and insulin resistance. Rev Assoc Med Bras, 61: 72-80.

Basta G., Lazzerini G., Del Turco S., Ratto G.M., Schmidt A.M. and De Caterina R. (2005) At Least 2 Distinct Pathways Generating Reactive Oxygen Species Mediate Vascular Cell Adhesion Molecule-1 Induction by Advanced Glycation End Products. Arterioscler Thromb Vasc Biol, 25: 1401-1407.

Benbow S.J., Wallymahmed M.E. and MacFarlane I.A. (1998) Diabetic peripheral neuropathy and quality of life. QJM, 91: 733-737.

Bimenya G.S., Nzarubara G.R., Kiconco J., Sabuni S. and Byarugaba W. (2003) The accuracy of self monitoring blood glucose meter systems in Kampala Uganda. Afr Health Sci, 3: 23-32.

Brownlee M., Vlassara H. and Cerami A. (1984) Nonenzymatic glycosylation and the pathogenesis of diabetic complications. Ann Intern Med, 101: 527-537.

Comitti R., Racchetti G., Gnocchi P., Morandi E. and Galante Y.M. (1987) A monoclonal-based, two-site enzyme immunoassay of human insulin. J Immunol Methods, 99: 2537.

Danesh J., Collins R., Peto R. and Lowe G.D.O. (2000) Haematocrit, viscosity, erythrocyte sedimentation rate: meta-analyses of prospective studies of coronary heart disease. Eur Heart J, 21: 515-520.

Davi G. and Patrono C. (2007) Platelet activation and atherothrombosis. N Engl J Med, 357: 2482-2494.

Davies M., Brophy S., Williams R. and Taylor A. (2006) The Prevalence, Severity, and Impact of Painful Diabetic Peripheral Neuropathy in Type 2 Diabetes. Diabetes Care, 29: 1518-1522.

Demirtas L., Degirmenci H., Akbas E.M., Ozcicek A., Timuroglu A., Gurel A. and Ozcicek F. (2015) Association of hematological indicies with diabetes, impaired glucose regulation and microvascular complications of diabetes. Int J Clin Exp Med, 8: 11420-11427.

Devangelio E., Santilli F., Formoso G., Ferroni P., Bucciarelli L., Michetti N., Clissa C., Ciabattoni G., Consoli A. and Davi G. (2007) Soluble RAGE in type 2 diabetes: association with oxidative stress. Free Radic Biol Med, 43: 511-518.

Edwards J.L., Vincent A.M., Cheng H.T. and Feldman E.L. (2008) Diabetic neuropathy: mechanisms to management. Pharmacol Ther, 120: $1-34$. 
Gardmark M., Hoglund A. and Hammarlund-Udenaes M. (1998) Aspects on Tail-Flick, Hot-Plate and Electrical Stimulation Tests for Morphine Antinociception. Basic Clin Pharmacol Toxicol, 83: 252258.

Gasparyan A.Y., Ayvazyan L., Mikhailidis D.P. and Kitas G.D. (2011) Mean platelet volume: a link between thrombosis and inflammation? Curr Pharm Des, 17: 47-58.

George G.S., Uwakwe A.A. and Ibeh G.O. (2013) Glycated haemoglobin, glucose and insulin levels in diabetic treated rats. CJPAS, 7: 2223-2226.

Gooch C. and Podwall D. (2004) The diabetic neuropathies. Neurologist, 10: 311-322.

Goyal B.R., Parmar K., Goyal R.K. and Mehta A.A. (2011) Beneficial role of telmisartan on cardiovascular complications associated with STZinduced type 2 diabetes in rats. Pharmacol Rep, 63: 956-966.

Guo Z., Yan X., Wang L., Wu J., Jing X. and Liu J. (2016) Effect of Telmisartan or Insulin on the Expression of Adiponectin and its Receptors in the Testis of Streptozotocin-Induced Diabetic Rats. Horm Metab Res, 48: 404-412.

Harati Y. (2007) Diabetic neuropathies: unanswered questions. Neurol Clin, 25: 303-317.

Hardikar P.S., Joshi S.M., Bhat D.S., Raut D.A., Katre P.A., Lubree H.G., Jere A., Pandit A.N., Fall C.H.D. and Yajnik C.S. (2012) Spuriously High Prevalence of Prediabetes Diagnosed by HbA1c in Young Indians Partly Explained by Hematological Factors and Iron Deficiency Anemia. Diabetes Care, 35: 797-802.

Hassan N.A., El-Bassossy H.M., Mahmoud M.F. and Fahmy A. (2014) Caffeic acid phenethyl ester, a 5-lipoxygenase enzyme inhibitor, alleviates diabetic atherosclerotic manifestations: Effect on vascular reactivity and stiffness. Chem-Biol Interact, 213: 28-3. 7

Hayashi K., Kojima R. and Ito M. (2006) Strain differences in the diabetogenic activity of streptozotocin in mice. Biol Pharm Bull, 29: 1110-1119.

Huang D., Yang C., Wang Y., Liao Y. and Huang K. (2009) PARP-1 suppresses adiponectin expression through poly)ADP-ribosyl)ation of PPAR \{gamma $\}$ in cardiac fibroblasts. Cardiovasc Res, 81: 98107.

Huang T.J., Price S.A., Chilton L., Calcutt N.A., Tomlinson D.R., Verkhratsky A. and Fernyhough P. (2003) Insulin Prevents Depolarization of the Mitochondrial Inner Membrane in Sensory Neurons of Type 1 Diabetic Rats in the Presence of Sustained Hyperglycemia. Diabetes, 52: 21292136.

Hussain S., Algaem M. and Numan I. (2014) Anti-inflammatory Effects of Telmisartan and Valsartan in Animal Model of Airways Inflammation. Pharmacologia, 5: 149-154.

Kanade R.V., van Deursen R.W., Harding K. and Price P. (2006) Walking performance in people with diabetic neuropathy: benefits and threats. Diabetologia, 49: 1747-1754.

Kislinger T., Tanji N., Wendt T., Qu W., Lu Y., Ferran L.J., Taguchi A., Olson K., Bucciarelli L., Goova M., Hofmann M.A., Cataldegirmen G., D'Agati V., Pischetsrieder M., Stern D.M. and Schmidt A.M. (2001) Receptor for Advanced Glycation End Products Mediates Inflammation and Enhanced Expression of Tissue Factor in Vasculature of Diabetic Apolipoprotein E-Null Mice. Arterioscler Thromb Vasc Biol, 21: 905-910. 
Kodiatte T.A., Manikyam U.K., Rao S.B., Jagadish T.M., Reddy M., Lingaiah H.K. and Lakshmaiah V. (2012) Mean platelet volume in Type 2 diabetes mellitus. $J \quad L a b$ Physicians, 4: 5-9.

Lau T.W., Lam F.F., Lau K.M., Chan Y.W., Lee K.M., Sahota D.S., Ho Y.Y., Fung K.P., Leung P.C. and Lau C.B. (2009) Pharmacological investigation on the wound healing effects of Radix Rehmanniae in an animal model of diabetic foot ulcer. $J$ Ethnopharmacol, 123: 155-162.

Lenzen S. (2008) The mechanisms of alloxan- and streptozotocin-induced diabetes. Diabetologia, 51: 216-226.

Lester E. (1989) The Clinical Value of Glycated Haemoglobin and Glycated Plasma Proteins. Ann Clin Biochem, 26: 213-219.

Lin L., Park S. and Lakatta E.G. (2009) RAGE signaling in inflammation and arterial aging. Front Biosci (Landmark Ed) 14: 1403-1413.

Luevano-Contreras C. and Chapman N. (2010) Dietary advanced glycation end products and aging. Nutrients, 2: 1247-1265.

Mahmoud A.M. (2013) Hematological alterations in diabetic rats - Role of adipocytokines and effect of citrus flavonoids . EXCLI J, 12: 647-657.

Maskos K., Fernandez-Catalan C., Huber R., Bourenkov G.P., Bartunik H., Ellestad G.A., Reddy P., Wolfson M.F., Rauch C.T., Castner B.J., Davis R., Clarke H.R.G., Petersen M., Fitzner J.N., Cerretti D.P., March C.J., Paxton R.J., Black R.A. and Bode W. (1998) Crystal structure of the catalytic domain of human tumor necrosis factor-\{alpha $\}$-converting enzyme. PNAS, 95: 3408-3412.

McLennan S., Yue D.K. and Twigg S.M. (2006) Molecular aspects of wound healing in diabetes. Primary Intention, 14: 8-13.
Menz H.B., Lord S.R., St George R. and Fitzpatrick R.C. (2004) Walking stability and sensorimotor function in older people with diabetic peripheral neuropathy. Arch Phys Med Rehabil, 85: 245-252.

Mishra M., Kumar H. and Tripathi K. (2008) Diabetic delayed wound healing and the role of silver nanoparticles. Dig $J$ Nanomater Biostruct, 3: 49-54.

Morse E.E., Kalache G., Germino W. and Stockwell R. (1981) Increased electronic mean corpuscular volume induced by marked hyperglycemia. Ann Clin Lab Sci, 11: 184-187.

Nakamura K., Yamagishi S., Nakamura Y., Takenaka K., Matsui T., Jinnouchi Y. and Imaizumi T. (2005) Telmisartan inhibits expression of a receptor for advanced glycation end products (RAGE) in angiotensin-II-exposed endothelial cells and decreases serum levels of soluble RAGE in patients with essential hypertension. Microvasc Res, 70: 137-141.

Nirala B.K., Perumal V. and Gohil N.K. (2015) Glycated serum albumin stimulates expression of endothelial cell specific molecule- 1 in human umbilical vein endothelial cells: Implication in diabetes mediated endothelial dysfunction. Diabetes Vasc Dis Res, 12: 290-297.

Norata G.D., Garlaschelli K., Grigore L., Tibolla G., Raselli S., Redaelli L., Buccianti G. and Catapano A.L. (2009) Circulating soluble receptor for advanced glycation end products is inversely associated with body mass index and waist/hip ratio in the general population. Nutr Metab Cardiovasc Dis, 19: 129-134.

Otton R., Soriano F.G., Verlengia R. and Curi R. (2004) Diabetes induces apoptosis in lymphocytes. $J$ Endocrinol, 182: 145-156.

Peppa M., Stavroulakis P. and Raptis S.A. (2009) Advanced glycoxidation 
products and impaired diabetic wound healing. Wound Repair Regen, 17: 461-472.

Plosker G.L. and White W.B. (2008) Telmisartan/Hydrochlorothiazide: a review of its use as fixed-dose combinations in essential hypertension. Drugs, 68: 1877-1899.

Punzi H.A., Dahlof B., Webster D., Majul C.R., Oigman W., Olvera R., Seeber M., Kobe M. and Schumacher H. (2013) The effects of telmisartan and amlodipine in treatment-naive and previously treated hypertensive patients: a subanalysis from a $4 \times 4$ factorial design study. Clin Exp Hypertens, 35: $330-340$.

Ramos K.M., Jiang Y., Svensson C.I. and Calcutt N.A. (2007) Pathogenesis of Spinally Mediated Hyperalgesia in Diabetes. Diabetes, 56: 1569-1576.

Reed M.J., Meszaros K., Entes L.J., Claypool M.D., Pinkett J.G., Brignetti D., Luo J., Khandwala A. and Reaven G.M. (1999) Effect of masoprocol on carbohydrate and lipid metabolism in a rat model of Type II diabetes. Diabetologia, 42: 102-106.

Sharma S., Kulkarni S.K., Agrewala J.N. and Chopra K. (2006) Curcumin attenuates thermal hyperalgesia in a diabetic mouse model of neuropathic pain. Eur $J$ Pharmacol, 536: 256-261.

Sheetz M.J. and King G.L. (2002) Molecular understanding of hyperglycemia's adverse effects for diabetic complications. JAMA, 288: 2579-2588.

Szkudelski T. (2001) The mechanism of alloxan and streptozotocin action in B cells of the rat pancreas. Physiol Res, 50: 537-546.

Tanaka Y., Uchino H., Shimizu T., Yoshii H., Niwa M., Ohmura C., Mitsuhashi N., Onuma T. and Kawamori R. (1999) Effect of metformin on advanced glycation endproduct formation and peripheral nerve function in streptozotocininduced diabetic rats. Eur $J$ Pharmacol, 376: 17-22.

Tong M., Tuk B., Shang P., Hekking I.M., Fijneman E.M.G., Guijt M., Hovius S.E.R. and van Neck J.W. (2012) Diabetes-Impaired Wound Healing Is Improved by Matrix Therapy With Heparan Sulfate Glycosaminoglycan Mimetic OTR4120 in Rats. Diabetes, 61: 2633-2641.

Tong P.C., Lee K.F., So W.Y., Ng M.H., Chan W.B., Lo M.K., Chan N.N. and Chan J.C. (2004) White Blood Cell Count Is Associated With Macro- and Microvascular Complications in Chinese Patients With Type 2 Diabetes. Diabetes Care, 27: 216-222.

Tsunekawa T., Hayashi T., Suzuki Y., Matsui-Hirai H., Kano H., Fukatsu A., Nomura N., Miyazaki A. and Iguchi A. (2003) Plasma Adiponectin Plays an Important Role in Improving Insulin Resistance With Glimepiride in Elderly Type 2 Diabetic Subjects. Diabetes Care, 26: 285-289.

Tulloch-Reid M.K., Hanson R.L., Saremi A., Looker H.C., Williams D.E., Krakoff J. and Knowler W.C. (2004) Hematocrit and the Incidence of Type 2 Diabetes in the Pima Indians. Diabetes Care, 27: 2245-2246.

Turner N.C., Wood L.J., Foster M. and Gueremy T. (1994) Effects of PAF, FMLP and opsonized zymosan on the release of ECP, elastase and superoxide from human granulocytes. Eur Respir J, 7: 934940.

Vinik A.I., Erbas T., Park T.S., Nolan R. and Pittenger G.L. (2001) Platelet Dysfunction in Type 2 Diabetes. Diabetes Care, 24:14761485. 
Wei M., Ong L., Smith M.T., Ross F.B., Schmid K., Hoey A.J., Burstow D. and Brown L. (2003) The streptozotocin-diabetic rat as a model of the chronic complications of human diabetes. Heart Lung Circ, 12: 44-50.

Wild S., Roglic G., Green A., Sicree R. and King H. (2004) Global Prevalence of Diabetes: Estimates for the year 2000 and projections for 2030. Diabetes Care, 27: 1047-1053.

Winocour P.D., Laimins $M$. and Colwell J.A. (1984) Platelet survival in streptozotocin-induced diabetic rats. Thromb Haemost, 51: 307-312.

Woo S.J., Ahn S.J., Ahn J., Park K.H. and Lee K. (2011) Elevated systemic neutrophil count in diabetic retinopathy and diabetes: a hospitalbased cross-sectional study of 30,793 Korean subjects. Invest Ophthalmol Vis Sci, 52: 7697-7703.

Yamagishi S., Matsui T., Nakamura K., Takeuchi M. and Inoue H. (2008) Telmisartan inhibits advanced glycation end products (AGEs)elicited endothelial cell injury by suppressing AGE receptor (RAGE) expression via peroxisome proliferator-activated receptorgammaactivation. Protein Pept Lett, 15: 850-853.

Yeom E., Byeon H. and Lee S.J. (2016) Effect of diabetic duration on hemorheological properties and platelet aggregation in streptozotocin-induced diabetic rats. Sci Rep, 6: 21913.

Zhang Q., Xiao X., Li M., Li W., Yu M., Zhang H., Sun X., Mao L. and Xiang H. (2012) Telmisartan improves kidney function through inhibition of the oxidative phosphorylation pathway in diabetic rats. J Mol Endocrinol, 49: 35-46.

Zychowska M., Rojewska E., Przewlocka B. and Mika J. (2013) Mechanisms and pharmacology of diabetic neuropathy - experimental and clinical studies. Pharmacol Reports, 65: 1601-1610.

\section{التأثير الوقائي الجزئي للتلميسارتان في الاعتلال العصبي المحيطي الناتج عن مرض السكري من

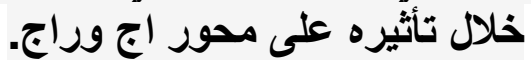

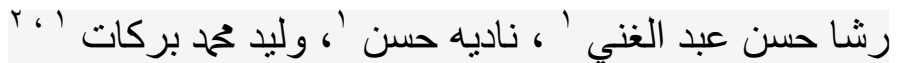

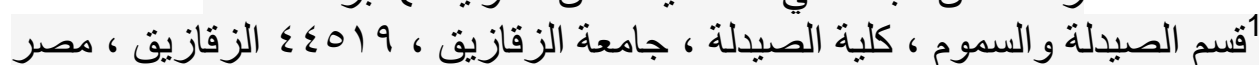

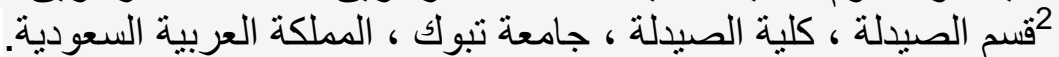

تم العثور على تر اكم لمنتوجات الغليكاين المتقدمة (اج )في الأشخاص الأصحاء المسنين و أثناء تركيزات

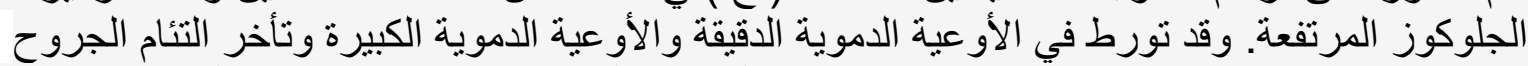

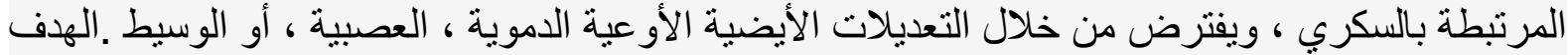

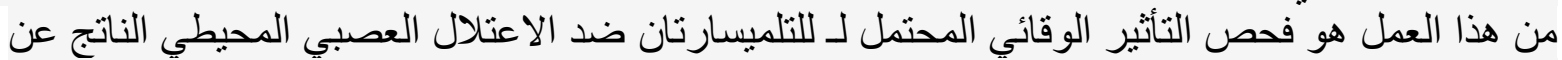

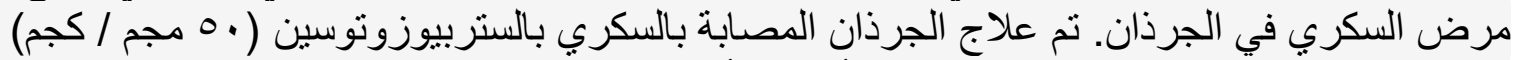

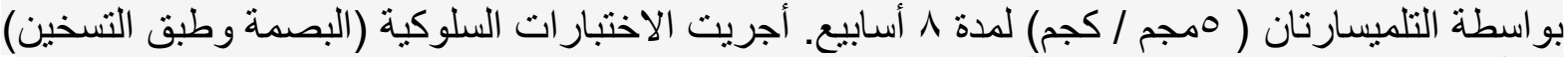

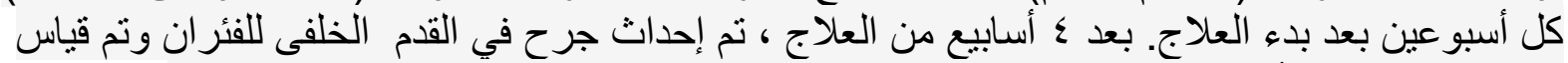

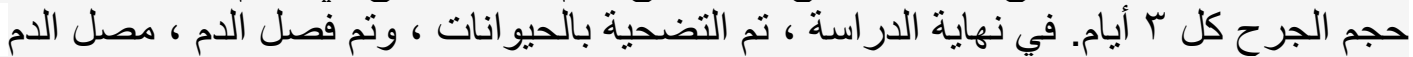

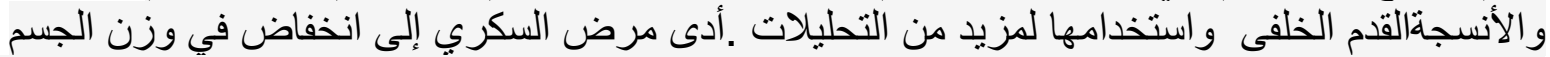

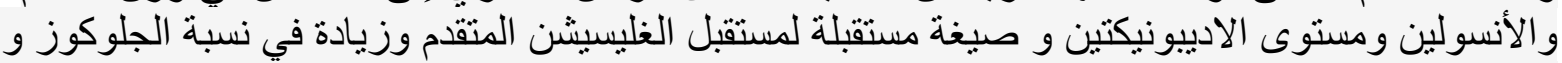

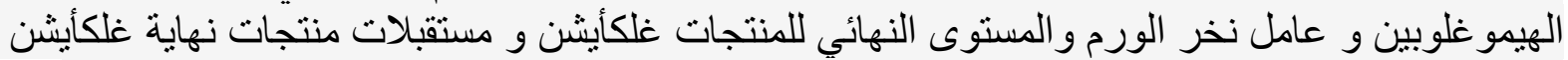
المتقدمة تعبير مقارنة بمجموعة التحكم. وارتبط هذا مع ضعف الأداء في اختبار ات السلوك وتأخر التئام 
الجروح. أدى العلاج باستخدام التلميسارتان إلى زيادة معنوية في وزن الجسم ، و اديبونيكتين المصل ،

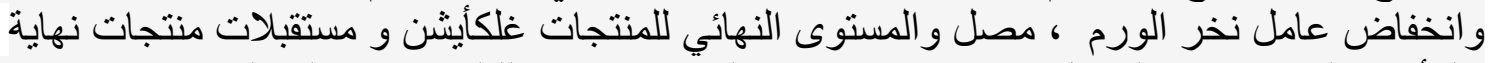

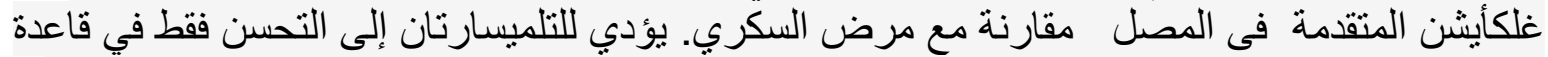

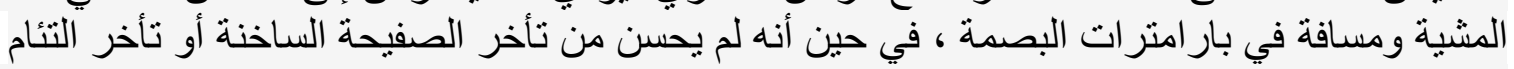

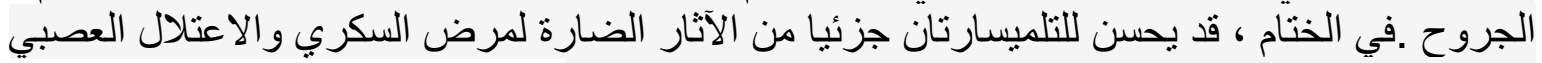

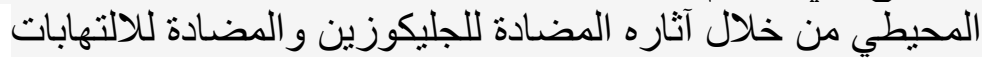

